\title{
A Note on the Persistence of Residual
}

\section{Income $^{1}$}

\section{JOACHIM LANDSTRÖM}

Uppsala University

Department of Business Studies

ABSTRACT: This paper investigates the behavior of residual income scaled by beginning of period book value, i.e., residual return on equity (ROE), by performing panel unit root tests as well panel regression tests on Swedish data. Results show that residual return on equity does not follow a random walk, nor is it transitory, yet it is much more transitory than what previous studies indicate. The study also proposes a method to design similar studies such that they can use data from privately held firms.

Key words: Accounting; Valuation; Arbitrage; No arbitrage; Rational expectations; Abnormal earnings, Residual income, Industry returns, Return on equity. Data availability: The reader can upon request get a copy of the data used to perform the tests.

\footnotetext{
${ }^{1}$ Paper presented in a financial analysis parallel session at EAA's $33^{\text {rd }}$ Annual Congress, 2010, Istanbul. 
JEL Classification: D41; D53; G12; L1; M41.

\section{Introduction}

The persistence of residual income has been investigated in several studies (Bauman 1999; Myers 1999; Dechow et al. 1999; McCrae and Nilsson 2001; Choi et al. 2006; Callen and Morel 2001; Giner and Iñiguez 2006). The median value of the persistence parameter in these studies is 0.54 .

Table 1. Estimated persistence parameters

\begin{tabular}{|c|c|c|c|}
\hline Study & Estimate & Firms & $\overline{\mathrm{N}}$ \\
\hline Bauman (1999) a & 0.223 & 665 & 6,171 \\
\hline Myers (1999)a & 0.234 & 2,601 & 44,980 \\
\hline Dechow et al. (1999) b & 0.62 & & 50,133 \\
\hline McCrae and Nilsson $(2001)_{b}$ & 0.523 & & 1,339 \\
\hline Choi et al. $(2006)_{b}$ & 0.49 & & 114,844 \\
\hline Callen and Morel (2001)a & 0.469 & 676 & 19,789 \\
\hline Ota $(2002)_{a}$ & 0.67 & 674 & 21,986 \\
\hline Giner and Iñiguez $(2006)_{b}$ & $0.61-0.82$ & 124 & 834 \\
\hline $\begin{array}{l}\text { a Uses the mean group (MG) estimator. } \\
\text { b Uses the ordinary least squares (OLS) }\end{array}$ & estimator. & & \\
\hline
\end{tabular}

The empirical studies reported in the table above uses panel data having many crosssections (large $N$ ) and relatively few years (small $T$ ) when they estimate the persistence of residual income. All studies either pool the data and run cross sectional analysis, i.e., pooled ordinary least squares (OLS) regression, or they apply a mean group (MG) estimator when estimating the persistence of residual income.

No study reports any deliberations on the consequences of choosing pooled OLS regression, or of choosing the mean group estimator when $T$ is small. Nor do they discuss the validity of the applied regression model given the underlying data generating process.

Furthermore, the studies that use pooling do not report results from model specifications tests, hence it is not possible to assess the validity of pooling. 
The previous studies above tests Ohlson's (1995) linear information dynamics model and they do not allow for a stochastic cost of capital. Nor do they consider the consequence of possible rational expectations equilibrium.

This study estimates the persistence of residual income using accounting data from public as well as non-public Swedish firms and it extends previous studies in at least five directions. First, it extends these studies by performing the assessment of the persistence of residual income using an unbiased panel regression method. Second, the tests allow for a stochastic cost of capital as discussed in Feltham and Ohlson (1999). Third, it tests for the possibility of rational expectations equilibrium. Four, the study extends previous studies by presenting a new method to measure residual income that allows for analysis of non-publicly traded firms. Finally, it presents a Swedish empirical study almost only to be matched in scope by studies based on US data since it uses approximately 23,461 firm-years for its tests.

This study finds that an unbiased measure of the persistence of residual income is 0.28 measured on Swedish data. Panel unit root tests show that the residual income (scaled by beginning of period book value) is not randomly walking.

The study also shows that pooled OLS regression is not applicable and overestimates the persistence of residual income with almost 50 percent, which means than many results from previous studies most likely are biased and needs revision. I also show that other panel regression methods such as the within group (WG) estimator and the residual effect (RE) estimator also are biased and hence not applicable for dynamic panel regression analysis using financial accounting data. The WG method underestimates the persistence of residual income with more than 30 percent.

The remainder of the text is organized as follows. Section II presents no arbitrage model based on unbiased and biased accounting. Section III poses the study's hypotheses and 
hypothesis tests. Section IV presents the sample, operationalizations, and descriptive statistics. Results are presented in Section V and conclusions in Section VI.

\section{Model}

\subsection{Introduction}

Ohlson (1995) assumes risk neutral preferences in deriving his model while empirical studies (e.g., Dechow et al. 1999; McCrae and Nilsson 2001; Giner and Iñiguez 2006) test the model assuming risk averse preferences trough a constant cost of capital.

Feltham and Ohlson (1999) generalize Ohlson (1995) and Feltham and Ohlson (1995) by using a risk-adjustment index that originally appears in Rubinstein (1976) and they present a model that use stochastic cost of capital. This is a more general model than using a constant cost of capital model.

The Feltham and Ohlson (1999) model can be further restricted by introducing linear risk preferences such that it becomes equivalent to a constant cost of capital model. However, as Feltham and Ohlson (1999) note, such restrictions are relatively arbitrary prohibits the cost of capital from varying with macro variables such as interest rates, or with the states of the economy, or with micro variables such as the firm's operating or financial leverage.

There is considerable empirical evidence that expected returns are time-varying (Shiller 1981; Campbell 1991; Fama and French 1997; Jagannathan and Zhenyu 1996). Time varying expected returns implies the necessity to use variable cost of capital. This is sometimes done when the persistence of residual income is tested (Callen and Morel 2001; Ota 2002). However, then only the risk-free rate in the CAPM varies while the risk preferences are constant.

Considering CAPM's inability to explain the returns on stocks (e.g., Jagannathan and Zhenyu 1996), since the earnings response coefficient studies indicates that market returns are (negatively) associated to interest rates (Collins and Kothari 1989), and given the analysis 
provided by Feltham and Ohlson (1999), I base this study on the stochastic model proposed by Feltham and Ohlson (1999) and hence allow for a stochastic cost of capital.

\subsection{No arbitrage residual income with stochastic cost of capital}

Corollary 2 in Feltham and Ohlson (1999) shows that the market price of the firm is equal to the present value of all future risk-adjusted residual income, $\mathrm{E}_{t}^{*}\left[R E_{t+\tau}\right]$ when they are discounted using the term-structure of the riskless interest rate, $R_{t+\tau}=1+r_{t+\tau}$, where $r$ is the riskless interest rate for a single period $(t+\tau-1, t+\tau)$ That is:

$$
P_{t}=B V_{t}+\sum_{t+\tau}^{\infty} R_{t+\tau}^{-\tau} \cdot \mathrm{E}_{t}^{*}\left[R I_{t+\tau}\right]
$$

The Feltham and Ohlson (1999) model measures the capital charge using the product of the riskless spot rate and the beginning-of-period book value of equity, which implies:

$$
R I_{t+\tau} \equiv E_{t+\tau}-r_{t+\tau} \cdot B V_{t+\tau-1}
$$

in which $\quad E_{t} \equiv D_{t}+B V_{t}-B V_{t-1}$

$D_{t}=$ Dividends net of other shareholder related transactions in period $t$ $B V_{t}=$ Book value of equity in period $t$

Feltham and Ohlson (1999) show that with homogenous beliefs, concave and timeadditive utility functions, the risk-adjusted residual income becomes:

$$
\mathrm{E}_{t}^{*}\left[R I_{t+\tau}\right]=\mathrm{E}_{t}\left[R I_{t+\tau}\right]-\operatorname{cov}\left(\mathrm{E}_{t}\left[R I_{t+\tau}\right], Q_{t+\tau}\right)
$$

The component $-\operatorname{cov}\left(\mathrm{E}_{t}\left[R I_{t+\tau}\right], Q_{t+\tau}\right)$ in (II.3) is the risk-adjustment and since it is a one-period component it follows that the risk-adjustment no longer is limited to be a fixed capital charge. By adding further restrictions to the utility function, it is possible to derive CAPM, but this study refrains from this due to the previous arguments.

\subsection{No arbitrage and unbiased accounting}

Let expected Goodwill be defined as $\mathrm{E}_{t}\left[G W_{t+\tau}\right] \equiv \mathrm{E}_{t}\left[P_{t+\tau}\right]-\mathrm{E}_{t}\left[B V_{t+\tau}\right]$ and define unbiased accounting as when $\mathrm{E}_{t}\left[G W_{t+\tau}\right]=0$ for all periods. This definition of unbiased 
accounting is stricter than that defined by Feltham and Ohlson (1995) who define it as $\mathrm{E}_{t}\left[G W_{t+\tau}\right] \rightarrow 0$ as $\tau \rightarrow \infty$, but is closer to a conventional view on goodwill. By forcing the expected goodwill to be zero for all periods, together with the no arbitrage assumption, it follows that that $\mathrm{E}_{t}^{*}\left[R I_{t+\tau}\right]=0$ for all periods and it implies that $\mathrm{E}_{t}\left[R I_{t+\tau}\right]=\operatorname{cov}\left(\mathrm{E}_{t}\left[R I_{t+\tau}\right], Q_{t+\tau}\right)$ for all periods, which means that the investor only receives compensation for taking risk.

Dividing (II.2) with beginning-of-period book value re-expresses residual income into residual return on equity, RROE, and substituting this into (II.3) leads to:

$$
\mathrm{E}_{t}^{*}\left[R R O E_{t+\tau}\right]=\mathrm{E}_{t}\left[R R O E_{t+\tau}\right]-\operatorname{cov}\left(\mathrm{E}_{t}\left[R R O E_{t+\tau}\right], Q_{t+\tau}\right)
$$

where:

$$
R R O E_{t+\tau}=R O E_{t+\tau}-r_{t+\tau}
$$

hence it follows that:

$$
\mathrm{E}_{t}\left[R O E_{t+\tau}\right]=\mathrm{E}_{t}\left[r_{t+\tau}\right]+\operatorname{cov}\left(\mathrm{E}_{t}\left[R R O E_{t+\tau}\right], Q_{t+\tau}\right)
$$

In a no-arbitrage setting, with unbiased accounting, it follows that the residual return on equity is just enough to compensate for the risk taken by the investor and as long as it is a risky investment, the return on equity is expected to be greater than the riskless interest rate $\left(R O E_{t+\tau}>r_{t+\tau}\right)$.

\subsection{No arbitrage and biased accounting}

From (II.4) and (II.6) above, a relation is established between the accounting based rate of return and the market rate of return such that they always equal and are greater than the riskless rate of return. In reality we can expect them to differ since the accounting system is biased due to its prudence principle. It is therefore necessary to consider the effects of biased accounting on the relation between the accounting based rate of return and the market rate of return in a no arbitrage setting. 
Since $\mathrm{E}_{t}\left[R I_{t+\tau}\right]=\operatorname{cov}\left(\mathrm{E}_{t}\left[R I_{t+\tau}\right], Q_{t+\tau}\right)$ in a no-arbitrage setting, it follows that $\mathrm{E}_{t}\left[R O E_{t+\tau}\right]=\mathrm{E}_{t}\left[r_{t+\tau}\right]+\operatorname{cov}\left(\mathrm{E}_{t}\left[R R O E_{t+\tau}\right], Q_{t+\tau}\right)$ which means that it is only necessary to specify the functional form of the risk adjustment index $Q_{t+\tau}$, and to measure the index, to be able to empirically estimate the expected ROE. The expected ROE can be used to measure the accounting bias.

Assuming a constant risk adjustment index implies that a linear risk tolerance method can measure the expected ROE. Adding further restrictions to a linear risk tolerance method can lead to the use of e.g., CAPM for measuring expected ROE. The outcome of such a strategy is therefore a constant cost of capital based RI-model similar to what has already been used in previous studies. As argued previously, this study assumes that the cost of capital is stochastic, which means that no further structure on the risk adjustment index is imposed. Hence it implies that CAPM is not available to measure the expected ROE, and no version of CAPM is therefore used in this study.

This study use the industry ROE as a tool to identify the accounting bias. That is, still assuming no arbitrage, firms within an industry are assumed to apply GAAP in a similar way, are assumed to have similar financial leverage, and are assumed to have similar operating leverage. This means that industry ROE is the sum of the riskless interest rate and the accounting bias, and (II.4) collapses to:

$$
\mathrm{E}_{t}^{*}\left[R R O E_{i, t+\tau}\right]=\mathrm{E}_{t}\left[R O E_{i, t+\tau}\right]-\mathrm{E}_{t}\left[R O E_{I, t+\tau}\right]
$$

Based on (II.7) I denote $R R O E_{i, t} \equiv R O E_{i, t}-R O E_{I, t}$ as the unbiased risk-adjusted residual return since accounting bias as well as risk compensation is removed with the use of industry ROE. 


\section{Hypotheses and hypotheses tests}

\subsection{Is the unbiased risk-adjusted residual return on equity randomly walking?}

No arbitrage implies a rational expectations equilibrium and a rational expectations equilibrium implies randomly walking stock prices (see e.g. Huang and Litzenberger 1993). Randomly walking stock prices implies random walk in stock returns too (a well-documented property, see e.g. Merton 1973; Campbell 1991; Fama and French 1997), which in this study's framework imply randomly walking risk-adjusted $R R O E$. To focus the argumentation, assume the following model:

$$
\begin{gathered}
\operatorname{RROE}_{i, t}=\alpha_{i}+\beta_{i} \cdot \operatorname{RROE}_{i, t-1}+u_{i, t} \\
R R O E_{i, t} \equiv R O E_{i, t}-\operatorname{ROE}_{I, t}
\end{gathered}
$$

Random walks in the risk-adjusted $R R O E$ imply that the persistence if residual income, $\beta$, is of unit root, which is this study's first null hypothesis:

$$
\beta_{i}=1
$$

The alternative is to have a stationary time series, which implies having $\left|\beta_{i}\right|<1$.

\subsection{Does the no arbitrage assumption hold?}

The null above (H0a) is based on a rational expectations equilibrium argumentation. Another alternative is to assume that we have a no arbitrage market with random exogenous chocks that drive the ex post realizations of the risk-adjusted $R R O E$ away from zero, and where arbitrageurs discover and trades on the arbitrage opportunity such that is disappears. This implies that the expectation of RROE is zero. In such a setting, it follows from (III.1) that the persistence parameter is zero and that the intercept is zero. This forms two complementary null hypotheses.

$$
\begin{aligned}
& \beta_{i}=0 \\
& \alpha_{i}=0
\end{aligned}
$$


The alternative to $\mathrm{H} 0 \mathrm{~b}$ is $\beta_{i}>0$, i.e., there is some persistence in the unbiased riskadjusted $R R O E$, and the alternative to H0c is $\alpha_{i}>0$. Having an intercept not equal to zero implies that monopoly profits or losses equal to $\alpha_{i} \cdot\left(1-\beta_{i}\right)^{-1}$ are present, and/or that there is an omitted variables problem. I assume that monopoly losses are unlikely and the test is onesided.

Rejecting both $\mathrm{HOa}$ and $\mathrm{HOb}$ implies having $\beta_{i} \in(0,1)$ which is neither consistent with rational expectation equilibrium nor consistent with a no arbitrage market since arbitrage opportunities are persistent. Furthermore, rejecting HOa, HOb and HOc implies that arbitrage opportunities and monopoly profits are present, and/or that there is an omitted variables problem.

\subsection{Estimation methods}

Two methods for estimating (III.1) are feasible. Time-series analysis allows the model to be fitted on each firm. Accounting data seldom appear in long time-series, which implies low powered results from individual time-series regressions. An alternative to individual specific time-series analysis is to use of the MG estimator. Myers (1999), Bauman (1999), and Callen and Morel (2001) use the MG estimator. Fama and French (2000) also apply the MG estimator but it is not directly related to this study.

The MG estimator is asymptotic in the number of time periods $(T)$ which implies that the mean group estimator may be biased in finite panels (Baltagi et al. 2008). Indeed Pesaran, Smith and Im (1996) test the finite sample properties of the mean group estimator and find that the bias can be serious for small $T$ panels and particularly when the ratio $N / T$ grows large. I therefore suspect that the mean group estimate may be biased in studies such as Myers (1999), Bauman, Callen and Morel (2001) and Fama and French (2000) who use accounting data panels having a large $N / T$-ratio. 
Another alternative is to pool the data by using estimation techniques that treat $T$ as fixed and that are asymptotic in $N$. This study follows Baltagi et al.'s (2008) recommendation pools the data, and uses estimation techniques asymptotic in $N$.

\subsubsection{Pooling data}

Consider (III.1) but this time without the individual-specific subscripts for the intercept and the persistence parameter. Dropping the subscript in (III.1) implies that the that an aggregation error may be introduced which bias the regression estimates. To be more specific, consider the following pooled model in which the white noise error term is contaminated by in individual-specific unobservable effect $\eta_{i}$ :

$$
\begin{gathered}
y_{i, t}=\alpha+\beta \cdot y_{i, t-1}+u_{i, t} \\
u_{i, t}=(1-\beta) \eta_{i}+v_{i, t} \\
\beta \in[0,1]
\end{gathered}
$$

where $y_{i, t}=R R O E_{i, t}$.

HOa assumes a unit root for all firms and it implies there can be no individual-specific unobservable effect. This is is implemented in model (III.2) since the individual-specific unobservable effect disappears trough the unit root process: $\beta=1 \Rightarrow(1-\beta) \eta_{i}=0 \Rightarrow u_{i, t}=v_{i, t}$.

\subsubsection{Test method for identifying unit roots}

Since we have that $\beta=1 \Rightarrow(1-\beta) \eta_{i}=0 \Rightarrow u_{i, t}=v_{i, t}$, it follows that if unit root is present it implies that there is no individual-specific unobservable effect and so that it is possible to estimate the model using OLS regression when testing for the presence of unit root.

Bond et al. (2005) use Monte Carlo simulations to test the robustness of several unit roots tests in dynamic panels and finds that a t-test of the OLS estimator of the equivalent to $\beta$ in (III.2) has the highest power to reject alternatives close to unit root. When $\beta<0.93$, they 
find that OLS no longer dominate other panel unit root tests. For such cases Bond et al. (2005) find that a differenced OLS estimator, originally proposed by Breitung and Meyer (1994), has highest power. Bond et al. (2005) conclude that both tests ought to be applied when testing for unit roots and this study tests HOa using both the OLS estimator and the differenced OLS estimator.

The differenced OLS estimator is:

$$
y_{i, t}-y_{i, 0}=\alpha+\beta \cdot\left(y_{i, t-1}-y_{i, 0}\right)+u_{i, t}
$$

The test statistic for the unit root tests are (Bond et al. 2005):

$$
t=\frac{\hat{\beta}-1}{\sqrt{\operatorname{VAR}(\hat{\beta})}}
$$

where

$$
\operatorname{VAR}(\hat{\beta})=\left(y_{t-1}^{\prime} y_{t-1}\right)\left(\sum_{i=1}^{N} y_{i, t-1}^{\prime} u_{i} u_{i}^{\prime} y_{i, t-1}\right)\left(y_{t-1}^{\prime} y_{t-1}\right)
$$

with $u_{i, t}=y_{i, t}-\beta y_{i, t-1}, y_{i, t}=\left(y_{i, 2}, \ldots, y_{i, T}\right)^{\prime}, y_{i, t-1}=\left(y_{i, 1}, \ldots, y_{i, T-1}\right)^{\prime}$, and $y_{t-1}=\left(y_{1, t-1}^{\prime}, \ldots, y_{N, t-1}^{\prime}\right)^{\prime}$ for $t=2, \ldots, T$.

\subsubsection{Estimating an unbiased measure of the persistence parameter in presence of no unit} root

Assuming that the unobserved individual-specific time-invariant component is zero, leads to a long-run value (provided that $|\beta|<1$ ) of (III.2) equal to $\alpha \cdot(1-\beta)^{-1}$. When this occurs it is possible to pool the data and estimate models such as (III.2) with OLS regression (Baltagi 2008). Such an estimation strategy is applied by Dechow, Hutton and Sloan (1999), McCrae and Nilsson (2001), Choi et al. (2006), and Giner and Iñiguez (2006) yet they do this without testing the validity of the assumption using the typical F-test. 
If the assumption of $\eta_{i}=0$ for all firms does not hold, it follows that $R R O E_{i, t-1}$ is predetermined since the correlation between $u_{i, t-1}$ and $R R O E_{i, t-1}$ is not zero. The OLS regression estimate is thus biased. Bond (2002) observes that it is an upward bias and that it can be severe on panels having many cross sections.

The accounting data generating process require, for example, each firm to use its own depreciation plans, which means that the unobserved individual-specific time-invariant component is not expected to be zero in accounting panels. Studies that use accounting panels are therefore not likely to have $\eta_{i}=0$. When $\eta_{i} \neq 0$ there are two alternatives. Either the regression model assumes $\sigma_{\eta_{i}}^{2}=0$ for all firms or it can assume $\sigma_{\eta_{i}}^{2} \sim \operatorname{NID}\left(\mu_{\eta}, \sigma_{\eta}^{2}\right)$.

Assuming $\sigma_{\eta_{i}}^{2}=0$ for all firms implies that it is possible to use the WG estimator to remove the fixed effect (Baltagi 2008, 295-298), as done by Landström (2007), while assuming $\sigma_{\eta_{i}}^{2} \sim N I D\left(\mu_{\eta}, \sigma_{\eta}^{2}\right)$ implies using a random effect (RE) estimator (Baltagi 2008, 298-302), as done by Callen and Segal (2005).

The lagged dependent variable is correlated with the errors since $\eta_{i} \neq 0$, which implies that both the WG and the RE estimators are biased. A well-specified unbiased panel regression estimator will have an estimator which is less than the OLS regression estimator and greater than the WG estimator when $\eta_{i} \neq 0$ (Bond 2002). Having a lagged dependent variable in the presence of $\eta_{i} \neq 0$ requires some other estimator than estimators based on OLS or GLS such as the difference general method of moments (difference GMM) or the system GMM (Bond 2002).

Difference GMM is weak when the persistence parameter is close to unit root since past levels provide little information about future changes, but the system GMM works well in such settings (Bond 2002; Roodman 2008b). System GMM is disadvantaged compared to 
difference GMM when the sampled values are far from their steady-state values (Roodman 2008a). This study only reports the results from the difference GMM approach.

\section{Sample selection, variable measurement, and descriptive statistics}

\subsection{Sample selection}

This study uses financial accounting data for Swedish public as well as non-public manufacturing companies supplied by Statistics Sweden. It covers all such firms over the period of 1977 to 1994 . The data supplied by Statistics Sweden is used in the national accounts statistics for measuring e.g., GDP.

Statistics Sweden use imputation when data are missing. Either Statistics Sweden impute the last financial years' data, or they impute the industry's arithmetic average (Eriksson 2003). These imputations are removed in this study.

When one firm acquires another there is a structural change in the surviving firm. If the structural change is greater than 20 percent, measured on value added, it is classified as a new firm with its own time-series of accounting data.

\subsection{Outlier detection and removal}

This study uses this biweight method having $c=9$ to identify outliers. An observation is classified as an outlier when it is farther than \pm 3 biweight standard deviations from the biweight location estimate. Setting the biweight constant to nine is approximately equivalent to six standard deviations (Mosteller and Tukey 1977). Mosteller and Tukey (1977) report that the biweight method having $c=9$ estimates robust confidence intervals having more than 90 percent efficiency in large samples.

Common methods to remove outliers are winsorising and trimming. See e.g. Dechow et al. (1999). Winsorising and trimming are pragmatic approaches that may lead to the deletion of too economically important variables. Since Mosteller and Tukey (1977) report 
that a more than 90 percent efficiency for the biweight method in large samples I use this method to reduce the risk of deleting economically important variables

\subsection{Measuring the firm's residual return on equity}

\subsubsection{Measuring the return on equity}

The return on equity is in this study defined as $R O E_{t} \equiv E_{t} B V_{t-1}^{-1}$, where $E$ is earnings before taxes and before items affecting comparability ${ }^{2}, B V$ is the book value of equity ${ }^{3}$.

\subsubsection{Industry classification}

This study classifies the industry using the Swedish industry classification system SNI92. Industries are measured at the three-digit level, as e.g. Cheng (2005), and as suggested by Gupta and Huefner (1972), except for industries having less than four firms. Industries are measured on the two-digit level when there are less than four firms at the three-digit level.

\subsubsection{Measuring the industry-specific return on equity}

Relating the firm-specific rate-of-return to its industry equivalent is not new and there is a discussion on the validity of comparing firm-specific ratios with industry-specific ratios.

See e.g., Lev and Sunder (1979), McDonald and Morris (1984, 1985), and by Sudarsanam and Taffler (1995) for such a discussion.

Model (II.7) implies that there is a linear relationship between the firm ratio and the industry ratio. McDonald and Morris $(1984,1985)$ investigate the possible linearity between firm ratios and industry ratios (measured as arithmetic means) and find such a relation. Thus it appears to be possible to use ratios for intra-industry comparison. McDonald and Morris $(1984,1985)$ only investigate these properties within the utility industry. Nor do they directly investigate a rate-of-return ratio. These weaknesses are mitigated by Sudarsanam and Taffler

\footnotetext{
${ }^{2}$ Items affecting comparability are extraordinary income and expenses and government subsidies.

${ }^{3}$ The book value of equity includes the equity proportion of untaxed reserves since the study is based on Swedish financial accounting data. This follows standard procedures in studies based on Swedish financial accounting data.
} 
(1995) who investigate six industries using e.g., a rate-of return measures, and find that a loglinear relationship dominates McDonald and Morris' $(1984,1985)$ assumed linear relation for rate-of return measures, and hence they argue that the median rather than the arithmetic average should be used as the location measure.

Rate-of returns have, due to the small-denominator effect, fat-tailed distributions as well as outliers and this is a likely reason to the difference in results between McDonald and Morris $(1984,1985)$ and Sudarsanam and Taffler (1995).

Industrial economics studies (e.g., Mueller 1977; Mueller and Cubbin 1990; Waring 1996; Cubbin and Geroski 1987; Geroski and Masson 1987; Geroski and Jacquemin 1988) use arithmetic average rate of return as a proxy for the industry return in empirical studies.

Rosenberger and Gasko (1983) investigate robust measures of location depending on the empirical distribution's tail-fatness and when the sample size is small. They show that the arithmetic average is only an efficient measure of the distribution's location when the empirical distribution is close to having a Gaussian shape. Otherwise Rosenberger and Gasko (1983) show that the median is the most efficient location estimate in most distributions patterns/size combinations, which support the findings by Sudarsanam and Taffler (1995).

Hence, McDonald and Morris' $(1984,1985)$ proposition to use the arithmetic average to measure the industry return is rejected by Sudarsanam and Taffler (1995) who instead suggest the median for measuring the industry return, and Rosenberger and Gasko (1983) show the robustness of the median as a location estimate. Rosenberger and Gasko (1983) also show that the broadened mean is preferable when the empirical distribution is fat-tailed and has more than 14 observations, but the median is just a special case of the broadened mean. These two measures are therefore be closely related. This study measure the residual return on equity as proposed by (II.7) in which the industry return is based on the industry median. 


\subsection{Descriptive statistics}

The data are screened and observations are gradually removed in a three-stage filtering process that starts with raw ROE and ends with RROE. The total data set consists of 24,909 observations and the first screen removes all observations having negative or zero beginning, and, or ending equity. After removing such observations there remain 24,291 observations. Table 2 shows a large discrepancy between the mean and the median after this process and this means that the data is affected by outliers. The observations are screened for detection of outliers, and 23,461 observations remain afterward. The difference between means and medians disappear after outliers have been deleted. Table 2 also shows that the removal of outliers greatly reduces the standard deviation, the skewness of the data as well as their kurtosis while keeping the interquartile range almost intact.

Table 2. Descriptive data of the sample

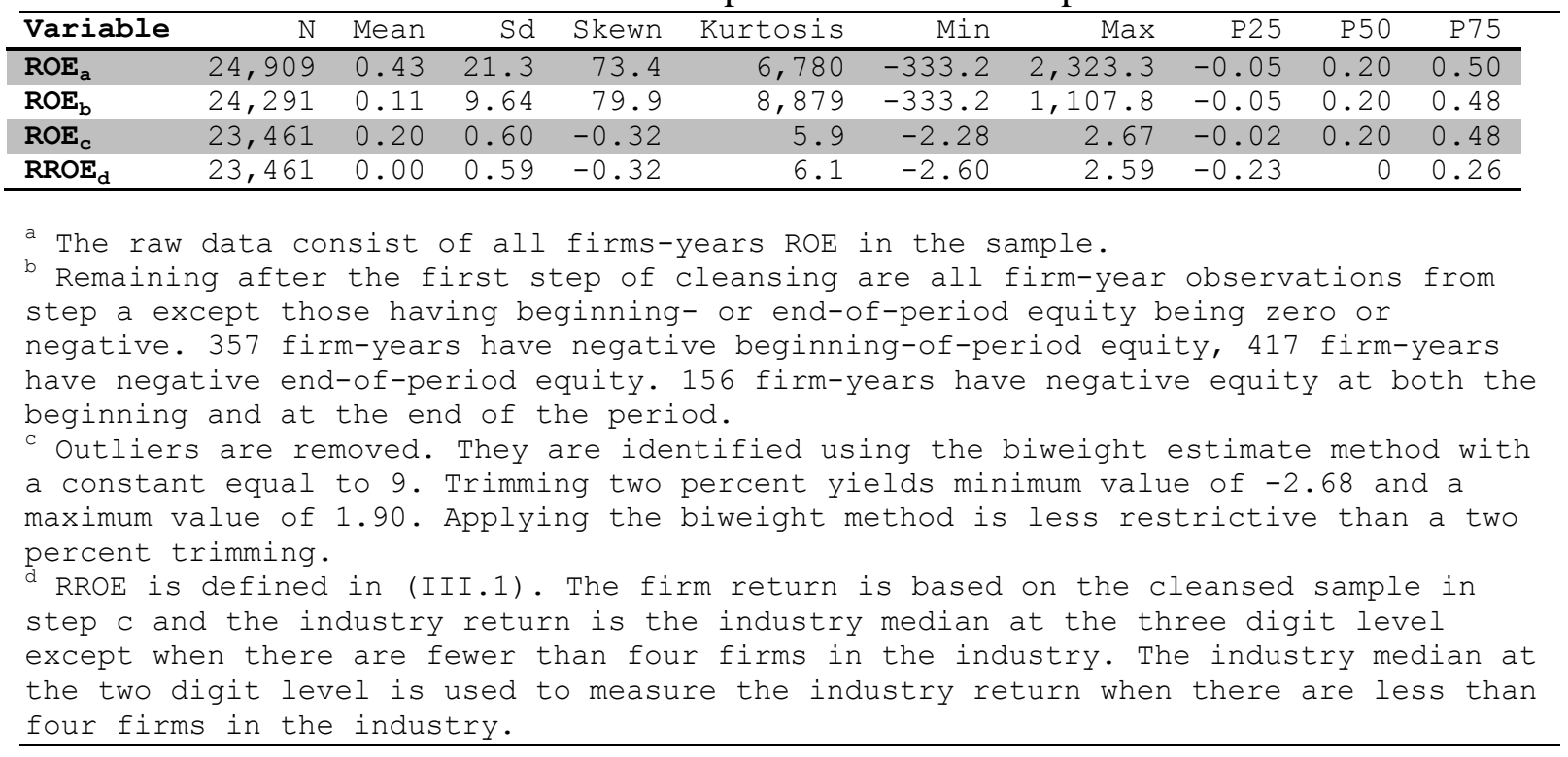

The final step converts firm-ROE into its corresponding RROE and, as Table 2 demonstrates, the mean as well as the median drops to zero. This is expected since firm-ROE is reduced by industry ROE. Figure 1 provides a histogram over the data. As seen in Table 2, RROE is slightly skewed. The skewness is so small that is it difficult to discern in Figure 1. 
Figure 1. Histogram of 23,461 RROE observations

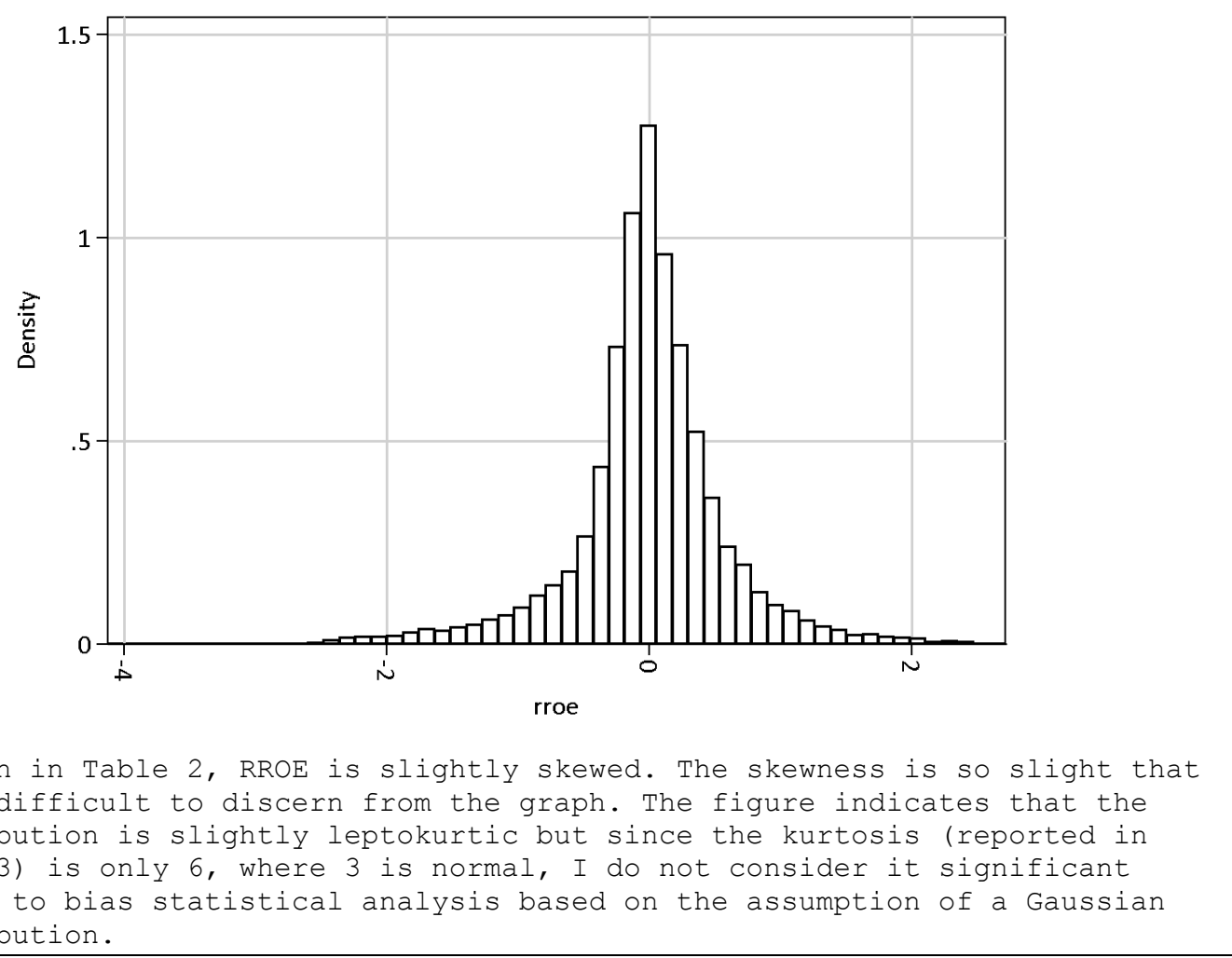

Table 3 below reports the number of observations per year as well as summing them up as totals.

Table 3. Number of observations in the sample

\begin{tabular}{lrrrrrrrrr}
\hline Year & 1978 & 1979 & 1980 & 1981 & 1982 & 1983 & 1984 & 1985 & 1986 \\
\hline Raw ROE & 807 & 861 & 1,499 & 1,506 & 1,535 & 1,512 & 1,545 & 1,590 & 1,626 \\
RROE & 756 & 826 & 1,412 & 1,409 & 1,445 & 1,433 & 1,461 & 1,521 & 1,544 \\
Difference & -51 & -35 & -87 & -97 & -90 & -79 & -84 & -69 & -82 \\
\hline \multirow{2}{*}{ Year } & 1987 & 1988 & 1989 & 1990 & 1991 & 1992 & 1993 & 1994 & Total \\
\hline Raw ROE & 1,649 & 1,673 & 1,731 & 1,641 & 1,645 & 1,471 & 1,309 & 1,309 & $\mathbf{2 4 , 9 0 9}$ \\
RROE & 1,552 & 1,603 & 1,637 & 1,538 & 1,523 & 1,346 & 1,220 & 1,235 & $\mathbf{2 3 , 4 6 1}$ \\
Difference & -97 & -70 & -94 & -103 & -122 & -125 & -89 & -74 & $-\mathbf{1 , 4 4 8}$ \\
\hline
\end{tabular}

Not all 23,461 observations are used in the statistical tests. E.g., the differenced GMM method and the Breitung and Meyer (1994) differenced OLS test requires that the lagged differenced dependent variables are available. Of the 23,461 observations, 16,482 observations (in 2,454 firms) fulfill the criteria for differenced GMM. The least restrictive 
tests are based on the pooled OLS method, the WG estimator and the OLS test for the presence of unit root in dynamic panels. 19,567 firm-years in 2,926 firms meet such criteria.

\subsubsection{Are individual-specific unobservable effects present?}

As argued in the section on estimation methods, pooled OLS regression is an estimation method that is only valid long as $\eta_{i}=0$ for all firms. Such an assumption is tested using the standard F-test for the presence of fixed effects (Baltagi et al. 2008). Table 4 and 5 below presents regression outputs for OLS and WG estimates of the RROE persistence as well as the F-test testing for the presence of fixed effects.

Table 4. OLS estimation

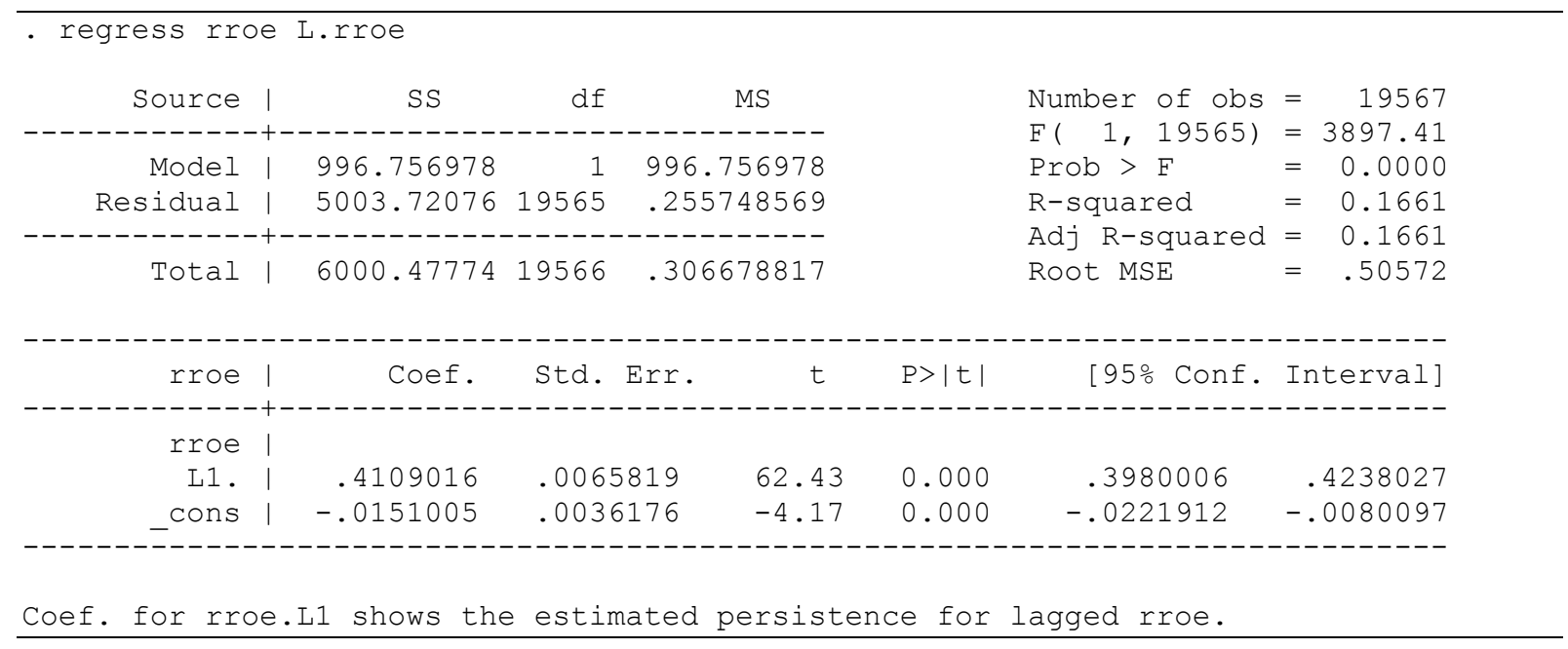


Table 5. WG estimation with the F-test for the presence of fixed effects

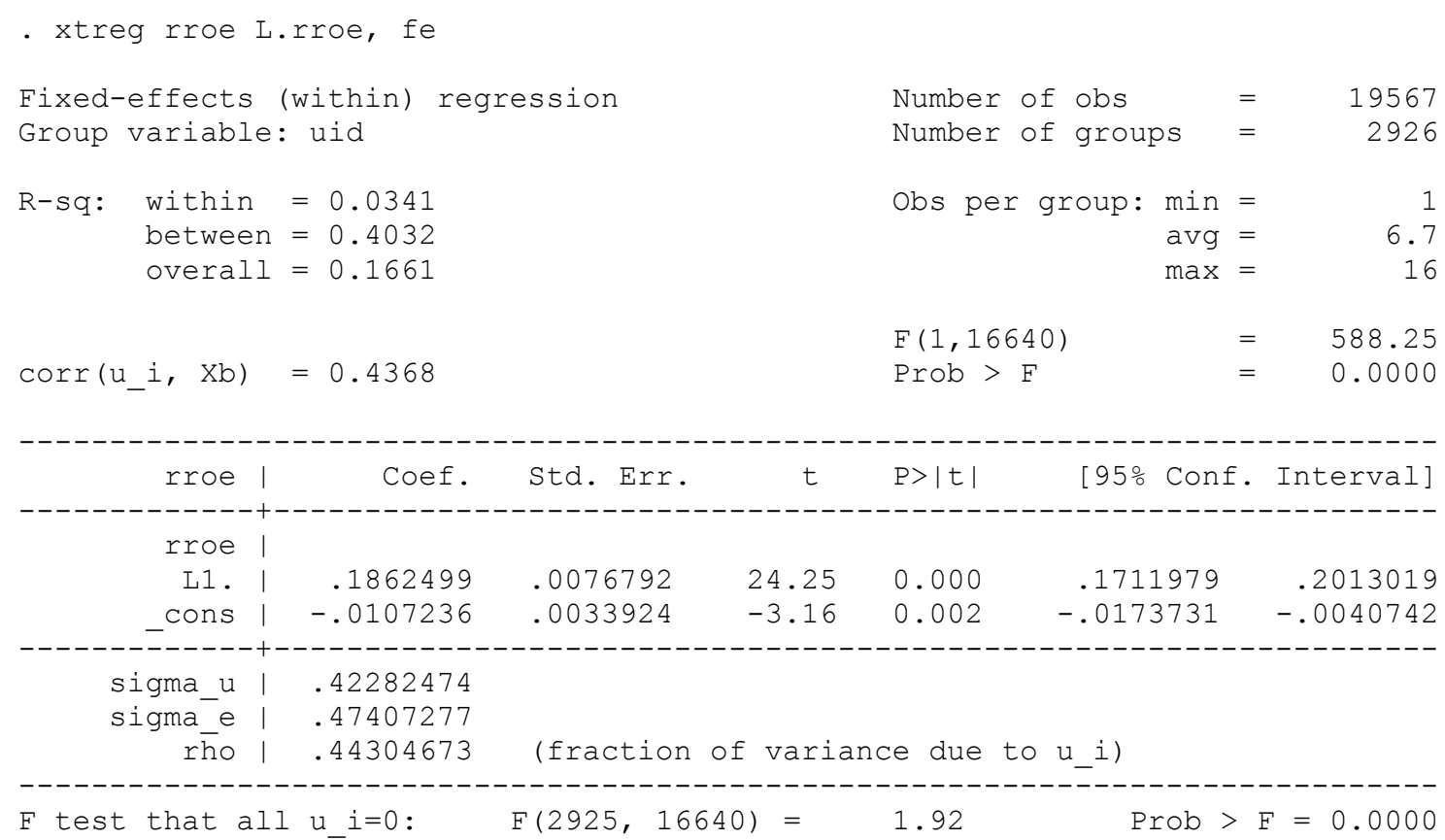

Table 4 and 5 show that both the OLS and the WG regression models are significant. The OLS F-test, $\mathrm{F}(1,19565)$ is very large and so is the WG F-test $\mathrm{F}(1,16640)$ too.

Table 5 show that the F-test for the presence fixed effects rejects the null since the test statistic, $\mathrm{F}(2925,16640)$, is 1.92 (its corresponding p-value is 0.000 ). This means that OLS regression is biased since the test detects the presence of individual-specific unobservable effects. That is $\eta_{i}$ in (III.2) is statistically significantly different from zero ${ }^{4}$.

OLS estimates in the presence of individual-specific unobservable effects are, as noted by Bond (2002), biased upward. Thus, the OLS estimate, which is 0.411 , provides the maximum attainable value for an unbiased estimate of RROE persistence. ${ }^{5}$

The alternative regression methods to test $\mathrm{HOb}$ and $\mathrm{HOc}$ are WG, RE, difference GMM or system GMM. WG and RE are also biased because of the lagged dependent variable. The

\footnotetext{
${ }^{4}$ A Hausman test is also performed, although not reported here, where the study investigate if the difference in RROE persistence is systematic. It rejects the null that the difference in RROE persistence is not systematic. This means that WG is preferred over RE.

${ }^{5}$ Dechow et al. (1999) and Bauman (1999) both measures the expected ROE to be equal to the long run return on the US stock market. When the study measure RROE similarly using the long run return on the Swedish stock market to measure RROE, it does not get a markedly different result from Table 4. This indicates the reliability to measure the RROE as I do, and therefore it supports the inclusion of non-public companies into similar studies.
} 
WG estimate provides the minimum value for an unbiased estimate of RROE persistence. The table above shows that the WG estimate is 0.186 .

Hence it follows that that an unbiased estimate of RROE persistence will be in the range of 0.41 and 0.19 , which is far from unit root. ${ }^{6}$

According to Bond (2002) and Roodman (2008b), System GMM is preferable over difference GMM when the estimate is close to unit root, but the likely range indicated by the OLS and the WG estimates is far from unit root. The difference GMM is therefore applied in the tests of $\mathrm{HOb}$ and $\mathrm{HOc}$.

The results in table 4 also show a large difference compared to McCrae and Nilsson (2001) who also use Swedish data. This study's OLS estimate is approximately 21 percent less than that reported by McCrae and Nilsson. One reason may be due to different data sets, but a major source for the difference likely pertains to the different operationalizations.

McCrae and Nilsson use CAPM to measure normal income whereas this study uses the industry median normal income. Accounting conservatism is a major factor that therefore differentiates these studies, where McCrae and Nilsson fail to mitigate the confounding effect from accounting conservatism.

\section{Results}

\subsection{Does RROE walk randomly?}

Hypothesis H0a proposes that RROE follows a random walk when no arbitrage is present. Random walk implies unit root and this can be tested. Bond et al. (2005) argue that two methods needs to be implemented to get a robust test for the presence of unit root.

The first test is based on (III.4) and the results are presented in Table 5 below.

\footnotetext{
${ }^{6}$ Since several studies use the MG estimator I have also estimated it. The MG estimate of the RROE persistence is estimated to be 0.49 . The median value is 0.17 . The MG mean estimate is thus severely biased. The $25^{\text {th }}$ percentile is -0.17 while the $75^{\text {th }}$ percentile is at 0.50 . Meyers (1999) does not report the mean estimate but his $25^{\text {th }}$ percentile is at -0.032 and his $75^{\text {th }}$ percentile is at 0.492 , while his median is at 0.234 . This is not too far from my values and presumable is his data also affected by estimate outliers (since he does not report the mean value and since he reports that more than 60 percent of the intercepts are negative).
} 
Table 5. OLS test for the presence of unit root in dynamic panels

\begin{tabular}{|c|c|c|c|c|}
\hline RROE | & Coef. & Std. Err. & t & $P>|t|$ \\
\hline RROE । & & & & \\
\hline L1. | & .4109016 & .0073499 & 80.15 & 0.000 \\
\hline
\end{tabular}

According to Table 5, having 19,565 degrees of freedom, the unit root test in (III.4) rejects the null of random walk in favor of its alternative; that is a stationary time series and hence we have that $\beta<1$.

Given the results from the pooled OLS regression reported in Table 4, the results in Table 5 are expected. But as Bond et al. (2005) note, the Breitung and Meyer (1994) differenced OLS test, (III.3), is needed for getting robust results as the deviation from unit root grows larger. Table 6 reports the results from this test.

Table 6. The Breitung and Meyer (1994) differenced OLS test for the presence of unit root in dynamic panels

\begin{tabular}{rrrrr}
\hline VAR & Coef. & Std. Err. & t & P $>|t|$ \\
VAR | & & & & \\
L1. I & .7556407 & .0216396 & 11.29 & 0.000 \\
\hline
\end{tabular}

The differenced OLS test also rejects the null in favor of stationarity at 6,781 degrees of freedom. Since the ordinary OLS test reported in Table 5 is less efficient than the differenced OLS test when the estimate deviates a far from unit root, it follows that the ordinary OLS test will over reject the null by reporting a too high t-statistic. The test should report a lower t-statistic since differenced OLS is more efficient in this case, which is also the case since the t-statistic drops from 80.15 to 11.29 . The differenced OLS test is nevertheless highly significant and taken together this study rejects H0a in favor of its alternative of $\beta<1$.

\subsection{Is RROE transitory?}

The ordinary OLS test and the differenced OLS test for unit root reject unit root in favor of a stationary time series. However, their estimates of the slope parameter are biased, 
and cannot be used for tests of hypothesis $\mathrm{HOb}$, or H0c, since the models use a lagged dependent variable. Furthermore, system GMM is not likely to be useful since the preliminary estimates of RROE persistence are far from unit root. This section therefore reports the results from differenced GMM estimates of the RROE persistence as well as relevant specification tests.

Roodman (2008a) notes that the introduction of time dummies removes the presence of universal time-related shocks which reduce the likelihood for having group wise heteroscedasticity. This study applies time dummies in the differenced GMM estimation to remove any presence of aggregate shocks that equally affect all firms. To further reduce any remaining heteroscedasticity, the study applies a two-step estimation method as suggested by Bond (2002). Bond (2002) also show that this method underestimates the standard errors and the study therefore calculates Windmeijer-corrected standard errors. Taken together this means that the study estimate the difference GMM using a robust two-step estimate that includes time-dummies, and its result is presented in the table below. 
Table 7. The differenced GMM estimation

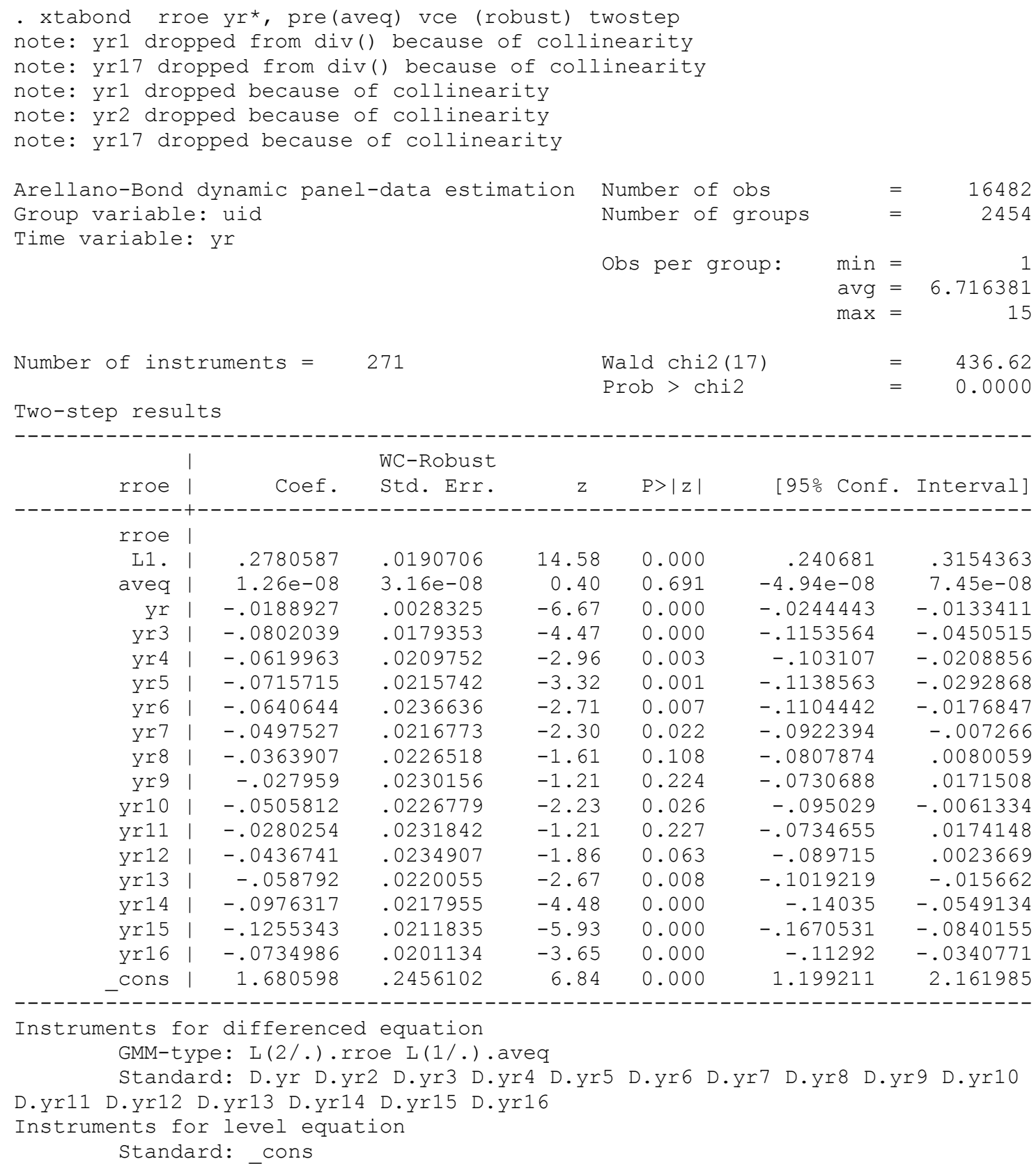

The Wald statistic shows that the model is highly significant using 271 instruments. The Arellano-Bond test for zero autocorrelation in first-differenced errors is also performed and shows that the first-differenced errors are serially correlated ( $\mathrm{p}$-value is 0.000 percent) but that they are not at higher orders (p-value is 7 percent), which is what is expected when the model is correctly specified. 
The regression model in the table above uses average book value of equity as a predetermined variable. The Sargan test reveals that not using a predetermined value rejects the null that the over identifying restrictions are valid. The test assumes spherical errors and in the presence of heteroscedasticity the Sargan test over rejects the null. Since I use time dummies and a two-step estimation technique to reduce the effects of heteroscedasticity, the rejection of the null in the Sargan test leads me to implement average equity as a predetermined variable. The Sargan test with average equity as a predetermined variable fails to reject the null with a chi square statistic of 284.8 at 253 degrees of freedom (the p-value is 8 percent).

From the OLS and the WG estimation reported in Table 4, it follows that an unbiased estimate of RROE persistence should be in the range of 0.41 and 0.19 . The estimated parameter is 0.28 , as can be seen in Table 7 , which is within the expected range. The t-test shows that RROE is significantly greater than zero, which means that HOb is rejected.

The unit root test and the rejection of $\mathrm{HOb}$, taken together show, that the persistence of RROE is significantly less than one and significantly greater than zero. Thus it follows that RROE is not randomly walking, nor is it transitory in the meaning that it goes away within a year.

Table 7 also reports a significantly positive intercept, which means that H0c is also rejected. The interpretation of this rejection is unclear since either it indicates, as previously argued, for the presence of monopoly rents, or it indicates the presence of omitted variables, or both.

The result in Table 7 also shows an unbiased parameter estimate that is approximately 30 percent lower than the pooled OLS estimate. This illustrates the danger of using pooled OLS to estimate persistence parameters in dynamic panel regression models such as Ohlson (1995). The discrepancy between the pooled OLS result and the differenced GMM result lead 
us to question the reliability of previous research based on pooled OLS regressions (e.g., Dechow et al. 1999; McCrae and Nilsson 2001; Choi et al. 2006; Giner and Iñiguez 2006). The RROE persistence in Table 7 is also different from the MG estimate, and it indicates the need to question the reliability of studies that tests the Ohlson (1995) model using the MG estimator (Callen and Morel 2001; Myers 1999; Ota 2002; Bauman 1999).

\section{Conclusions}

This study investigates the persistence of residual return on equity using a Swedish database having approximately 23,461 firm-years. I test the notion from rational expectations theory that residual return on equity is randomly walking using the model proposed by Feltham and Ohlson (1999). This is tested using an ordinary least squares regression method as well as a differenced ordinary least squares regression method, and both methods reject the null of unit root. I also test the notion of a no arbitrage setting where exogenous shocks create residual returns on equity that are transitory because of arbitrageurs. This null is also rejected in favor of its alternative of having persistent residual returns on equity. The persistence parameter is 0.28 and hence much less than what previously studies, such as that by McCrae and Nilsson (2001) who also use Swedish data, find.

I argue that part of the discrepancy between this study's findings and previous studies pertain to the fact that pooled ordinary least squares regression estimates (as used by most of the other studies) are biased upward and overestimates the persistence parameter. Another major source of difference between this study and other studies, is that this study tries to mitigate the confounding effects of accounting conservatism.

In balance, this study contributes to the accounting literature by providing empirical evidence from Sweden having a scope almost only to be matched by US data; by presenting empirical results based on Feltham and Ohlson's model (1999); by clearly connecting the model to both rational expectations theory and no arbitrage theory; by introducing a method 
that allows accounting studies to be based on non-publicly held firms; by introducing unbiased dynamic panel regression estimation procedures into this research field. 


\section{References}

Baltagi, B. H. 2008. Econometrics [electronic resource]. Berlin: Springer.

Baltagi, B. H., G. Bresson, and A. Pirotte. 2008. To Pool or Not to Pool. In The econometrics of panel data: fundamentals and recent developments in theory and practice, edited by L. Mátyás and P. Sevestre. Berling: Springer, 517-546.

Bauman, M. P. 1999. An empirical investigation of conservatism in book value measurement. Managerial Finance 25 (12):42-57.

Bond, S. R. 2002. Dynamic panel data models: a guide to micro data methods and practice. Portuguese Economic Journal 1 (2):141-162.

Bond, S. R., C. Nauges, and F. Windmeijer. 2005. Unit Roots: Identification and Testing in Micro Panels. In CEMMAP Working Paper No. CWP07/05: Centre for Microdata Methods and Practice.

Breitung, J., and W. Meyer. 1994. Testing for unit roots in panel data: Are wages on different bargaining levels cointegrated? Applied Economics 26 (4):353.

Callen, J. L., and M. Morel. 2001. Linear Accounting Valuation When Abnormal Earnings Are AR(2). Review of Quantitative Finance and Accounting 16 (3):191-204.

Callen, J. L., and D. Segal. 2005. Empirical Tests of the Feltham-Ohlson (1995) Model. Review of Accounting Studies 10 (4):409-429.

Campbell, J. Y. 1991. A variance decomposition for stock returns. Economic Journal 101 (405):157-179.

Cheng, Q. 2005. What Determines Residual Income? Accounting Review 80 (1):85-112.

Choi, Y.-S., J. F. O'Hanlon, and P. F. Pope. 2006. Conservative Accounting and Linear Information Valuation Models. Contemporary Accounting Research 23 (1):73-101.

Collins, D. W., and S. P. Kothari. 1989. An analysis of intertemporal and cross-sectional determinants of earnings response coefficients. Journal of Accounting and Economics $11(2-3): 143-181$.

Cubbin, J., and P. Geroski. 1987. The convergence of profits in the long run: Inter-firm and inter-industry comparisons. Journal of Industrial Economics 35 (4):427.

Dechow, P. M., A. P. Hutton, and R. G. Sloan. 1999. An empirical assessment of the residual income valuation model. Journal of Accounting and Economics 26 (1-3):1-34.

Eriksson, J. 2003. Treatment and editing of tax data for Swedish structural business statistics. Paper read at Conference of European Statisticians, October 2003, at Madrid.

Fama, E. F., and K. R. French. 1997. Industry costs of equity. Journal of Financial Economics 43 (2):153-193. 2000. Forecasting Profitability and Earnings. Journal of Business 73 (2):161.

Feltham, G. A., and J. A. Ohlson. 1995. Valuation and Clean Surplus Accounting for Operating and Financial Activities. Contemporary Accounting Research 11 (2):689731.

1999. Residual Earnings Valuation With Risk and Stochastic Interest Rates. Accounting Review 74 (2):165.

Geroski, P. A., and A. Jacquemin. 1988. The persistence of profits: A European comparison. Economic Journal 98 (391):375-389.

Geroski, P. A., and R. T. Masson. 1987. Dynamic market models in industrial organization. International Journal of Industrial Organization 5 (1):1-13.

Giner, B., and R. Iñiguez. 2006. An empirical assessment of the Feltham-Ohlson models considering the sign of abnormal earnings. Accounting \& Business Research 36 (3):169-190. 
Gupta, M. C., and R. J. Huefner. 1972. A Cluster Analysis Study of Financial Ratios and Industry Characteristics. Journal of Accounting Research 10 (1):77-95.

Huang, C.-F., and R. H. Litzenberger. 1993. Foundations for financial economics. Englewood Cliffs, N.J.: Prentice Hall.

Jagannathan, R., and W. Zhenyu. 1996. The Conditional CAPM and the Cross-Section of Expected Returns. Journal of Finance 51 (1):3-53.

Landström, J. 2007. The theory of Homo comperiens, the firm's market price, and the implication for a firm's profitability. Monography, Department of Business Studies, Uppsala University, Uppsala.

Lev, B., and S. Sunder. 1979. Methodological issues in the use of financial ratios. Journal of Accounting and Economics 1 (3):187-210.

McCrae, M., and H. Nilsson. 2001. The explanatory and predictive power of different specifications of the Ohlson (1995) valuation models. European Accounting Review $10(2): 315-341$.

McDonald, B., and M. H. Morris. 1984. The statistical validity of the ratio method in financial analysis: An empirical examination. Journal of Business Finance \& Accounting 11 (1):89-97.

1985. The Functional Specification of Financial Ratios: An Empirical Examination. Accounting \& Business Research 15 (59):223-228.

Merton, R. C. 1973. An Intertemporal Capital Asset Pricing Model. Econometrica 41 (5):867887.

Mosteller, F., and J. W. Tukey. 1977. Data analysis and regression : a second course in statistics. Reading, Mass.

Mueller, D. C. 1977. The Persistence of Profits above the Norm. Economica 44 (176):369380.

Mueller, D. C., and J. Cubbin. 1990. The dynamics of company profits : an international comparison. Cambridge: Cambridge University Press.

Myers, J. N. 1999. Implementing Residual Income Valuation With Linear Information Dynamics. Accounting Review 74 (1):1.

Ohlson, J. A. 1995. Earnings, Book Values, and Dividends in Equity Valuation. Contemporary Accounting Research 11 (2):661-687.

Ota, K. 2002. A test of the Ohlson (1995) model: Empirical evidence from Japan. International Journal of Accounting 37 (2):157-182.

Pesaran, M. H., R. Smith, and K. S. Im. 1996. Dynamic linear models for heterogenous panels. In The econometrics of panel data: a handbook of the theory with applications, edited by L. Mátyás and P. Sevestre. Dordrecht: Kluwer Academic, 145-195.

Roodman, D. 2008a. How to do Xtabond2: An Introduction to Difference and System GMM in Stata. In Center for Global Development Working Paper No. 103: Center for Global Development.

- 2008b. A Note on the Theme of Too Many Instruments. In Center for Global Development Working Paper No. 125: Center for Global Development.

Rosenberger, J. L., and M. Gasko. 1983. Comparing location estimators: Trimmed means, medians, and trimean. In Understanding Robust and Exploratory Data Analysis, edited by D. C. Hoaglin. New York: Wiley, 297-338.

Rubinstein, M. 1976. The Valuation of Uncertain Income Streams and the Pricing of Options. Bell Journal of Economics 7 (2):407-425.

Shiller, R. J. 1981. Do Stock Prices Move Too Much to be Justified by Subsequent Changes in Dividends? American Economic Review 71 (3):421.

Sudarsanam, P. S., and R. J. Taffler. 1995. Financial ratio proportionality and inter-temporal stability: An empirical analysis. Journal of Banking \& Finance 19 (1):45-60. 
Waring, G. F. 1996. Industry Differences in the Persistence of Firm-Specific Returns. American Economic Review 86 (5):1253-1265. 